\title{
Estimation of Hydraulic Roughness of Concrete Sewer Pipes
}

\author{
Kamaran Jamal Hama \\ Presidency of Sulaimaniyah Municicipality
}

\begin{abstract}
.
Supporting global population needs requires attention from experts in diverse fields and collaboration with local governments and the people needing assistance. For example, when covering natural disasters, reporters often focus on volunteer, corporate, and non-profit support while also interviewing individuals affected by events. Media personalities also highlight infrastructure upgrades but fail to elaborate on technological history and advances.

The focus of this qualitative content analysis was exploring the development, reliability, validity, and expanded use of Manning's roughness coefficient $(n)$ as related to concrete sewer pipes. Compared with non-concrete-lined waterways concrete-lined structures increase the flow water; however, tests to evaluate unobservable, the movement and flow rate of fluid, sediment, and other elements within sewer pipes was essential for engineers and served populations. Scientists discovered how the roughness of the pipes and internal elements, concrete density and composition, and other variables must be considered when designing sewer systems.

Researchers initially focused on the Manning roughness coefficient $n$ as a constant. Other factors explored in assorted sewer and water systems revealed the influence of $R e, R h, k, S o$, and $F r$ whereby $n$ is no longer a constant. Geographic and other factors to include fluid level and pipe angularity would influence and be affected by $n$. These discoveries rarely yield media coverage or remain cursory compared with politics or natural disasters. This study bridges the popular media and engineering refinements of concrete sewer systems gap by demonstrating how scientific study yields significant infrastructure cost-savings and improves quality of life. Future study areas include exploring opportunities to improve sewer systems in developing countries, expediting repairs or upgrading sewer systems damaged by a natural disaster, creating less-expensive and less-absorbing concrete to minimize costs, and expand eclectic scientific collaboration to improve sanitation for the growing global community.
\end{abstract}

Keywords: Urban Drainage, Concrete Pipe, Roughness Coefficient (n), Flow and sediment 